\title{
Soya isoflavones suppress phorbol 12-myristate 13-acetate-induced COX-2 expression in MCF-7 cells
}

\author{
Tak Yi Lau ${ }^{2}$ and Lai K. Leung ${ }^{1,2} *$ \\ ${ }^{1}$ Food and Nutritional Sciences Programme, The Chinese University of Hong Kong, Shatin, N.T., Hong Kong \\ ${ }^{2}$ Department of Biochemistry, Faculty of Medicine, The Chinese University of Hong Kong, Shatin, N.T., Hong Kong
}

(Received 12 March 2005 - Revised 13 September 2005 - Accepted 4 October 2005)

\begin{abstract}
Epidemiological studies indicate that Asian women have a lower incidence of breast cancer compared with their counterparts in the West, and soya consumption has been suggested as a contributory factor. Clinical and animal studies have revealed that cyclooxygenase-2 (COX-2) expression is associated with a risk of breast cancer. In the present study, we investigated the effect of soya isoflavones on the expression of COX-2 in the breast cell line MCF-7. Genistein, daidzein and equol were found to inhibit COX-2 expression induced by phorbol 12-myristate 13-acetate (PMA). Similar findings were observed in the COX-2 protein analysis. In order to study transcriptional control, a fragment of the $5^{\prime}$-flanking region of the $h C O X-2$ gene was amplified and inserted into a firefly luciferase reporter plasmid. The reporter assay indicated that the transactivation of the $h C O X-2$ promoter was induced by PMA, and activity was inhibited with the co-administration of genistein, daidzein or equol. An activator protein-1 (AP-1)/cyclic AMP response element binding protein (CREB) binding site $(-59 /-53)$ was identified in $h C O X-2$ promoter, and this could be critical in PMA-induced COX-2 expression. Truncation reporter plasmids with $(-70 /-36)$ and without $(-51 /-36)$ AP-1/CREB were constructed for subsequent analysis. The results revealed that the $h C O X-2$ promoter transactivation suppressed by isoflavone could be dependent on AP-1/CREB binding. Nonetheless, this study illustrated that the soya isoflavones reduced COX-2 expression, which could be important in the post-initiation events of breast carcinogenesis.
\end{abstract}

Genistein: Daidzein: Equol: COX-2: Breast cancer cells

The significance of prostaglandins in carcinogenesis has been identified in many studies. Human malignant tumours show increased concentrations of prostaglandins, which enhance cell proliferation, encourage angiogenesis and protect against apoptosis (Singh \& Lucci, 2002). Prostaglandins can be produced by cyclooxygenases (COX) in tumour tissues. Two forms of cyclooxygenase have been identified, namely COX-1 and COX-2. Because of its ubiquitous expression and the lack of difference observed between normal and malignant tissues (Gupta \& DuBois, 2001), COX-1 has drawn little attention in cancer research. COX-2 is an inducible form of cyclooxygenase, and its association with various cancers has been demonstrated (Soslow et al. 2000).

The role of COX-2 in breast cancer has previously been examined. Clinical studies have revealed that $\mathrm{COX}-2$ is overexpressed in the neovasculature of breast tumours, and COX-2 apparently most affects the later stages of cancer development. An overexpression of COX-2 in MCF-7 cells shortens the doubling time and augments the number of cells during the phase of exponential growth, as well as increasing the number of colony formations in soft agar, the invasion across Matrigel basement membrane (BD Biosciences, San Jose, CA, USA) and the expression of vascular endothelial growth factor (Prosperi et al. 2004). In another breast cancer cell line, Hs578T, overexpression of COX-2 activates metalloproteinase-2 (Takahashi et al. 1999). These activities may increase the invasiveness of cancer cells and facilitate metastasis. The mechanisms of altered gene expression may account for these undesirable effects. As revealed by Trifan \& Hla (2003), COX-2 may increase the expression of endothelial growth factor receptor, aromatase and $\mathrm{Bcl}-2$.

Activator protein-1 (AP-1) is a crucial transcriptional factor in tumour promotion (Dong et al. 1994). Previous study has indicated that AP-1 may share the response sequence $(-59$ / $-53)$ of the $h C O X-2$ gene with cAMP to initiate the transcription (Subbaramaiah et al. 2002b). Several pathways that involve AP-1 in COX-2 regulation have been identified, these being dependent on the activities of protein kinase $\mathrm{C}$ (PKC; Subbaramaiah et al. 1998), protein kinase A (PKA; Miller et al. 1998) or mitogen-activated protein kinase (MAPK, extracellular signal-regulated protein kinase (ERK)1/2; Sun et al. 2002) in a cell type-specific manner.

Women who take non-steroidal anti-inflammatory drugs have a reduced incidence of breast cancer (Howe et al. 2001). In animal studies, COX-2 inhibitors have shown some promising results on breast cancer prevention. Celecoxib slows the onset and progression of 7,12-dimethylbenz[a]anthraceneinduced mammary tumours in rats (Harris et al. 2000), 
whereas nimesulide reduces the incidence of tumours induced by 2-amino-1-methyl-6-phenylimidazol[4,5-b]pyridine (Nakatsugi et al. 2000). Moreover, celecoxib also delays the onset of mammary tumours in HER2/neu transgenic mice (Howe et al. 2002) and inhibits oestrogen receptor-negative MDA-MB-231 cell proliferation (Arun et al. 2001) in vitro. These results have demonstrated that COX-2 inhibition may protect against breast carcinogenesis.

Breast cancer is one of the most common cancers in women. Asian countries have lower incidences of breast cancer than the West; however, no difference in breast cancer incidence is found between Asian descendents and the rest of the population in America (Ziegler et al. 1993). This suggests that environment is a part of the aetiology of breast cancer, and soya consumption has been one of the major leads in investigation. Because various studies have supported the fact that soya isoflavones can protect against breast cancer, the investigation has extended to clinical trials (Greenwald, 2004).

The mechanism by which soya isoflavones may produce protection is still under scrutiny. Many negative or adverse effects of the compounds have also been reported in several studies. Allred et al. (2004) have even demonstrated that genistein was able to encourage the growth of tumours induced by $\mathrm{N}$-methyl-N-nitrosourea or tumours derived from MCF-7 cells. In addition, Murata et al. (2004) have shown that two metabolites of soya isoflavones can induce DNA damage. The interaction between soya isoflavones and the oestrogen receptor has been a major focus. However, our laboratory (Leung \& Wang, 2000; Po et al. 2002) has demonstrated that the apoptosis of MCF-7 cells induced by genistein is not related to oestrogen receptor antagonism.

Considering all the available information, the protection of soya isoflavone against breast cancer could be phenotypespecific and stage-selective. In the present study, we investigated the effect of soya isoflavones on the expression of COX-2, which is associated with the post-initiation stage of breast cancer (Prosperi et al. 2004).

\section{Materials and methods}

\section{Chemicals}

Genistein, daidzein, equol, phorbol 12-myristate 13-acetate (PMA) and the carrier solvent dimethylsulphoxide were purchased from Sigma Chemicals (St Louis, MO, USA). PD98059, bisindolylmaleimide I and 14-22 amide were obtained from EMD Biosciences Inc.(La Jolla, CA, USA). All other chemicals, unless stated, were acquired from Sigma Chemicals.

\section{Cell culture}

The protocol was previously described by Po et al. (2002). In brief, MCF-7 cells (a gift from Dr V. C. Jordan, Northwestern University, Chicago, IL, USA) were routinely cultured in RPMI-1640 media (Sigma Chemicals), supplemented with $10 \%$ fetal bovine serum (Invitrogen Life Technologies, Rockville, MD, USA) and antibiotics (50 U/ml penicillin, $50 \mu \mathrm{g} / \mathrm{ml}$ streptomycin), and incubated at $37^{\circ} \mathrm{C}$ and $5 \% \mathrm{CO}_{2}$. Three days before the experiment, the cultures were switched to RPMI-1640 phenol red-free media (Sigma Chemicals) and
$5 \%$ charcoal-dextran treated fetal bovine serum (Hyclone, UT, USA). Sub-confluent cell cultures were treated with PMA and various concentrations of isoflavone with dimethylsulphoxide as the carrier solvent. The final concentration of the solvent was $0.1 \% \mathrm{v} / \mathrm{v}$, and the control cultures received dimethylsulphoxide only.

\section{Luciferase reporter gene assay}

Construction of hCOX-2 activated luciferase reporter gene. A fragment with 1629 bp $(-1665$ to -36$)$ from the human $C O X-25^{\prime}$-flanking region was amplified from genomic DNA isolated from HeLa cells. Primers were designed with the incorporation of $M l u \mathrm{I}$ and $B g l \mathrm{II}$ restriction sites. The amplified product was then digested and sub-cloned into a firefly luciferase reporter vector pTA-Luc (BD Biosciences Clontech, Palo Alto, CA, USA), and the sequence accuracy was verified. This reporter plasmid was designated COX$2 \Delta 1$. Truncated promoters were amplified from the $1629 \mathrm{bp}$ fragment and subcloned into the same reporter vector. Five truncated promoter reporter plasmids, designated COX $-2 \Delta 2$ $(-1341 /-36)$, COX $-2 \Delta 3(-952 /-36), C O X-2 \Delta 4(-578 /$ $-36), \mathrm{COX}-2 \Delta 5(-70 /-36)$ and $\mathrm{COX}-2 \Delta 6(-52 /-36)$, were constructed. $\mathrm{COX}-2 \Delta 5(-70 /-36)$ and $\mathrm{COX}-2 \Delta 6$ $(-52 /-36)$ were designed to include or exclude AP-1/ CREB, which was the only identified response element within the sequence $-70 /-52$ of $h C O X-2$.

Dual luciferase assays. MCF-7 cells were seeded at $10^{5}$ cells/well in twenty-four-well plates. After $24 \mathrm{~h}$, the cells were transiently transfected with $4.0 \mu \mathrm{g} h C O X-2$ reporter plasmid and $1.0 \mu \mathrm{g}$ Renilla luciferase control vector pRL (Promega, Madison, WI, USA) in LipofectAmine (Invitrogen Life Technologies). After $16 \mathrm{~h}$, the medium was removed and the cells were treated with PMA, soya isoflavone or protein kinase inhibitors for $6 \mathrm{~h}$. The amounts of these two luciferases were determined using Dual-Luciferase Assay Kit (Promega). Luciferase bioluminescence was quantified by using a FLUOstar Galaxy plate reader (BMG LabTechnologies, Offenberg, Germany. The transactivation activities of the $h C O X-2$ promoter represented by firefly luciferase light units were then normalised with the light units of Renilla luciferase.

\section{Quantitative real-time PCR assay}

MCF-7 cells were seeded in a six-well plate for $1 \mathrm{~d}$ before treatment. The medium was removed, and cells were cultured in the presence of $1 \mu \mathrm{M}$ PMA and soya isoflavone. After $6 \mathrm{~h}$ treatment, total RNA was extracted from the cells using TRIzol reagent (Invitrogen, Carlsbad, CA, USA). The concentration and purity of RNA were determined by absorbance at 260/280 nm. First, DNA strands were synthesised from $3 \mu \mathrm{g}$ total RNA using oligo-dT primers and moloney murine leukemia virus reverse transcriptase (USB Corporation, Cleveland, $\mathrm{OH}$, USA). Target fragments were quantified by real-time PCR, and an ABI prism 7700 Sequence Detection System (Applied Biosystems, Foster City, CA, USA) was employed for this assay. Taqman/VIC minor groove binder probes and primers for COX-2 and glyceraldehyde-3-phosphate dehydrogenase (Assay-on-Demand $^{\mathrm{TM}}$ ) and real-time PCR Taqman Universal PCR Master Mix were all obtained from Applied Biosystems. PCR reactions were set up as described in the protocol, which 
was validated by the manufacturer. Signals obtained for GAPDH were used as a reference housekeeping gene to normalise the amount of total RNA amplified in each reaction. Relative gene expression data were analysed using the $2^{-\Delta \Delta C} \mathrm{~T}$ method (Livak \& Schmittgen, 2001).

\section{Western blot analysis}

Cells were washed once with PBS (pH 7.4) and harvested into a $1.5 \mathrm{ml}$ microtube with $0.5 \mathrm{ml}$ lysis buffer (PBS, $1 \% \mathrm{NP} 40$, $0.5 \%$ sodium deoxycholate, $0 \cdot 1 \%$ SDS). The lysis buffer contained protease inhibitors $(40 \mathrm{mg} / \mathrm{l}$ phenylmethyl sulphonylfluoride, $0.5 \mathrm{mg} / \mathrm{l}$ aprotinin, $0.5 \mathrm{mg} / \mathrm{l}$ leupeptin, $1.1 \mathrm{mmol} / \mathrm{l}$ EDTA and $0.7 \mathrm{mg} / \mathrm{l}$ pepstatin). The harvested cells were then lysed with a cell disruptor (Branson Ultrasonics Corp., Danbury, CT, USA) on ice for $30 \mathrm{~s}$. The protein concentration of cell lysate was determined by Dc protein assay (BioRad, Richmond, CA, USA). Lysate protein $50 \mu \mathrm{g}$ was separated on $10 \%$ SDS-PAGE and transferred on to an Immobilon Polyvinylidene difluoride membrane (Millipore, Bedford, MA, USA). Anti-COX-2 (Cayman Chemicals, Ann Arbor, Michigan, USA), anti-actin primary (Sigma Chemicals) and secondary antibodies conjugated with horseradish peroxidase (Santa Cruz Biotechnology, Santa Cruz, CA, USA) were used for protein detection. An enhanced chemiluminescence Detection Kit (Amersham, Arlington Heights, IL, USA) provided the chemiluminescence substrate for horseradish peroxidase, and the targeted protein was visualised by autoradiography.

\section{Statistical methods}

A Prism ${ }^{\circledR} 3.0$ software package (GraphPad Software, Inc., San Diego CA, USA) was utilised for statistical analysis. The results of the present study were compared by ANOVA and Bonferroni's method for multiple comparisons. The level of significance was set at $P<0 \cdot 05$.

\section{Results}

Effect of soya isoflavones on PMA-induced COX-2 mRNA expression

Cultures treated with PMA had a greater amount of COX-2 mRNA than did control cultures, the increase being greater than $500 \%$. The co-administration of daidzein, equol or genistein reduced the abundance of mRNA to a varying degree: genistein and equol appeared to be more potent than daidzein in inhibiting mRNA expression (Fig. 1).

Western blot analysis on COX-2 protein in cultures treated with PMA and soya isoflavones

After determining the quantities of mRNA, COX-2 expression at the protein level was also determined, as shown in Fig. 2. PMA induced COX-2 protein expression, and treatment with daidzein, equol or genistein reduced the amount of protein. Autoradiographic images of COX-2 protein expression are shown in Fig. 2(A), whereas Fig. 2(B) shows the average optical density obtained from two independent experiments.

Effect of soya isoflavones and inhibitors of PKC, PKA, and $M A P K$ on PMA-induced hCOX-2 promoter activities

MCF-7 cells were transfected with a $h C O X-2$ reporter construct, and luciferase activity was subsequently measured to reveal the transcriptional control of COX-2 expression. PMA induced luciferase activity $3-5$-fold. The co-administration of $0 \cdot 1,1,10$ or $100 \mu \mathrm{M}$-daidzein, equol or genistein produced a dose-dependent inhibition of promoter activity (Fig. 3(A)). Significant suppression occurred at $10 \mu \mathrm{M}$ or above for the three isoflavones tested. Adding $10 \mu \mathrm{M}$ of any of the isoflavones decreased the PMAinduced activity by $40 \%$. The combined effect of soya isoflavones on promoter activity was also addressed. Cultures treated

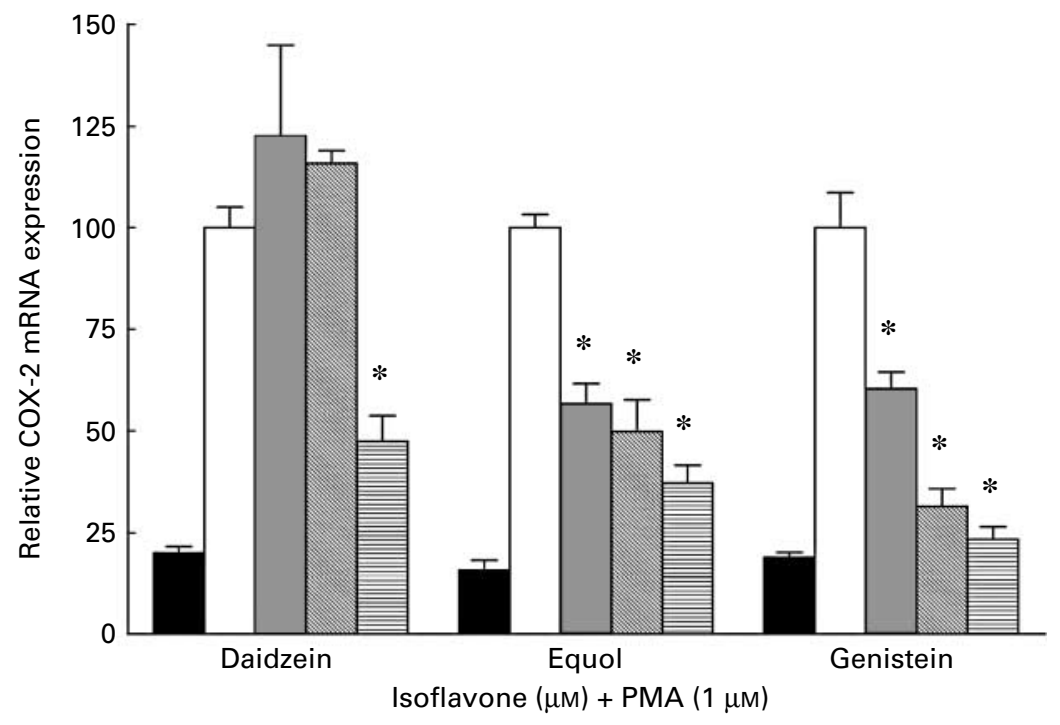

Fig. 1. Quantitative mRNA measurement of cyclooxygenase-2 (COX-2) expressed in MCF-7 cells co-treated with phorbol 12-myristate 13-acetate (PMA) and soya isoflavone. MCF-7 cells were seeded in six-well culture plates and treated with $1 \mu \mathrm{M}-\mathrm{PMA}$ and various concentrations of daidzein, equol and genistein. After $6 \mathrm{~h}$ treatment, RNA was extracted and assayed. Control cultures received only dimethylsulphoxide. Fig. 1 represents one set of two experiments performed with comparable results. Values are means with their standard errors, $n 3$. $\square$ Control; $\square 0 \mu \mathrm{M} ; \square 0.1 \mu \mathrm{M}$; $1 \mu \mathrm{M}$; 目 $10 \mu \mathrm{M}$. ${ }^{*}$ Significant $(P<0.05)$ difference from cultures treated only with PMA. 

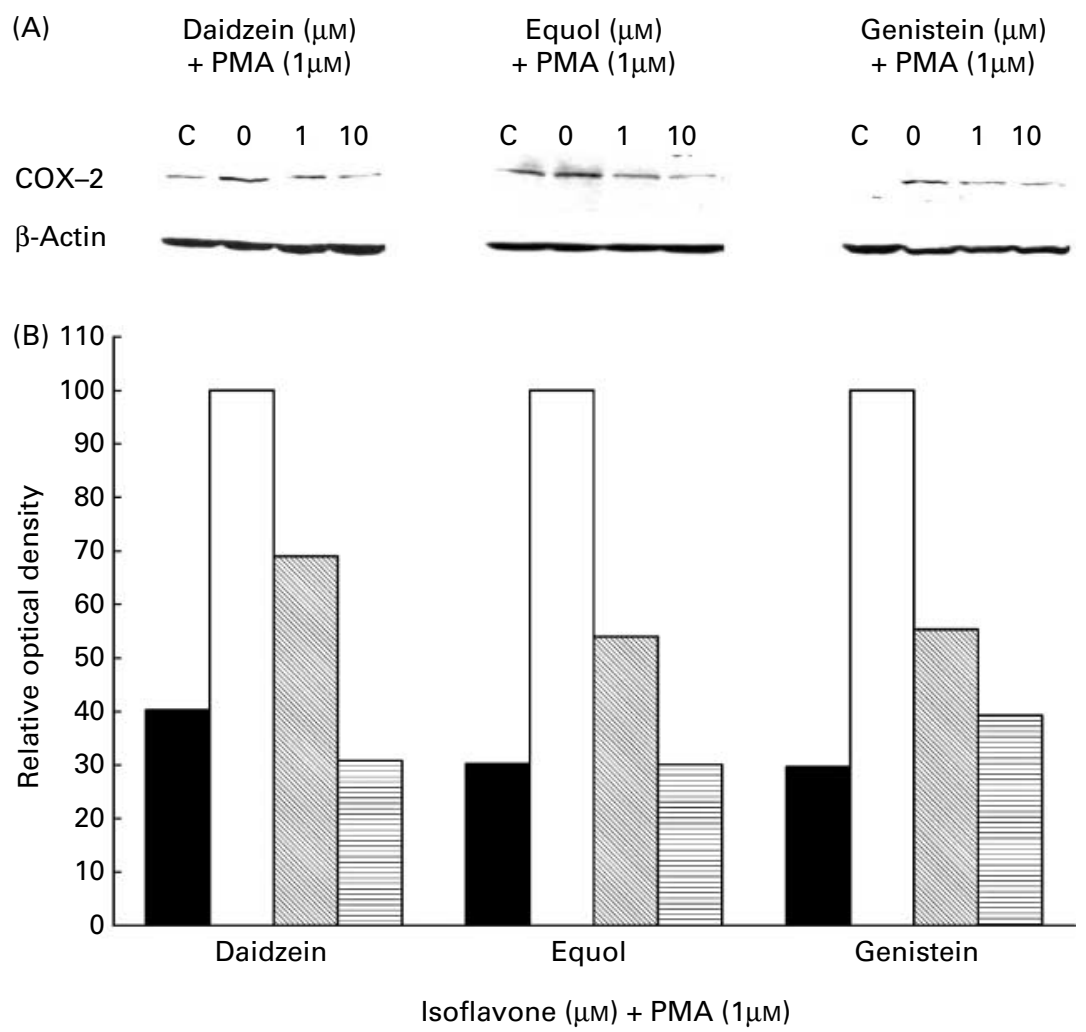

Fig. 2. Western blot analysis of cyclooxygenase-2 (COX-2) protein in cultures co-treated with phorbol 12-myristate 13-acetate (PMA) and soya isoflavone. MCF-7 cells were treated with $1 \mu \mathrm{mol} / \mathrm{I} \mathrm{PMA}$ and soya isoflavone, and cultured for $6 \mathrm{~h}$. Protein lysates were prepared for western blot analysis. The autoradiographs for the three isoflavones tested are shown in (A), and the optical density readings are presented in (B). Each blot was repeated once. $\mathrm{C}$, control culture with carrier solvent added only; 0,1 and 10 , isoflavone concentrations in $\mu \mathrm{M}$ co-treated with $1 \mu \mathrm{M}$-PMA. $\mathbf{\square}$ Control; $\square 0 \mu \mathrm{M} ; \mathbb{8} 1 \mu \mathrm{M} ;$ 目 $10 \mu \mathrm{M}$.

with $2 \mu \mathrm{M}$ of either genistein, daidzein or equol could not suppress the promoter activity induced by PMA. A significant reduction was, however, observed when the isoflavones were administered together. It appeared that the three isoflavones could initiate an additive effect (Fig. 3(B)).

Previous studies have indicated that PMA triggers COX-2 expression with the involvement of PKA (Miller et al. 1998), PKC (Subbaramaiah et al. 1998) or MAPK (ERK1/2; Sun et al. 2002) signalling pathways in different cell types, the predominant mechanism lying in the activation of AP-1/ CREB. 14-22 Amide, bisindolylmaleimide I and PD98059 are specific inhibitors of PKA, PKC and MAPK, respectively. The administration of inhibitors of PKC and MAPK substantially decreased $h C O X-2$ promoter-driven gene transactivation, whereas PKA inhibitor was not effective (Fig. 3(C)).

\section{Analysis of the PMA-induced hCOX-2 promoter profile}

$H C O X-2$ promoter segments activated by PMA were located by a series of truncated promoter reporter constructs. Figure 4 represents the PMA-induced activity for each construct normalised by the respective reporter activity without PMA treatment. Cultures transfected with $\mathrm{COX}-2 \Delta 5$ and $\mathrm{COX}-\Delta 6$ had a lower activity than those transfected with the other promoter constructs among the PMA-treated samples. The data implied that AP-1/CREB and other unknown elements located in the segment $-578 /-70$ were responsible for the induced transcriptional activity.
Effect of soya isoflavones and inhibitors of PKC, PKA and $M A P K$ on truncated hCOX-2 promoter-containing $A P-1 / C R E B$

Because AP-1/CREB had been identified as a significant contributor to PMA-induced $h C O X-2$ transactivity, the AP-1/ CREB-positive and AP-1/CREB-negative truncated promoter constructs, i.e. $\mathrm{COX}-2 \Delta 5$ and $\mathrm{COX}-\Delta 6$, were selected for subsequent analysis. The PMA-induced transactivity of $\mathrm{COX}-2 \Delta 5$ was erased by the administration of genistein, daidzein or equol, which represented a $50 \%$ decrease in the total activity (Fig. 5(A)). No significant difference in luciferase activity was observed for the same treatment performed on COX-2 26 .

Inhibitors of PKC, PKA and MAPK were also employed to test for the signalling pathways involved in the AP-1/CREB transactivation. Bisindolylmaleimide I and 14-22 amide treatments did not elicit any inhibition, whereas PD98059 was able to lower the induced COX-2 $\Delta 5$ activity (Fig. 5(B)). The result revealed a possible involvement of MAPK in AP-1/CREB activation of the $h C O X-2$ promoter.

\section{Discussion}

MCF-7 cells have been used as a model system for the study of oestrogen receptor-positive breast cancer (Simstein et al. 2003) and can be a viable model for studying the underlying mechanisms of soya's chemoprevention observed in animals (Upadhyaya \& EL Bayoumi, 1998). Making use of this cell model, 
(A)
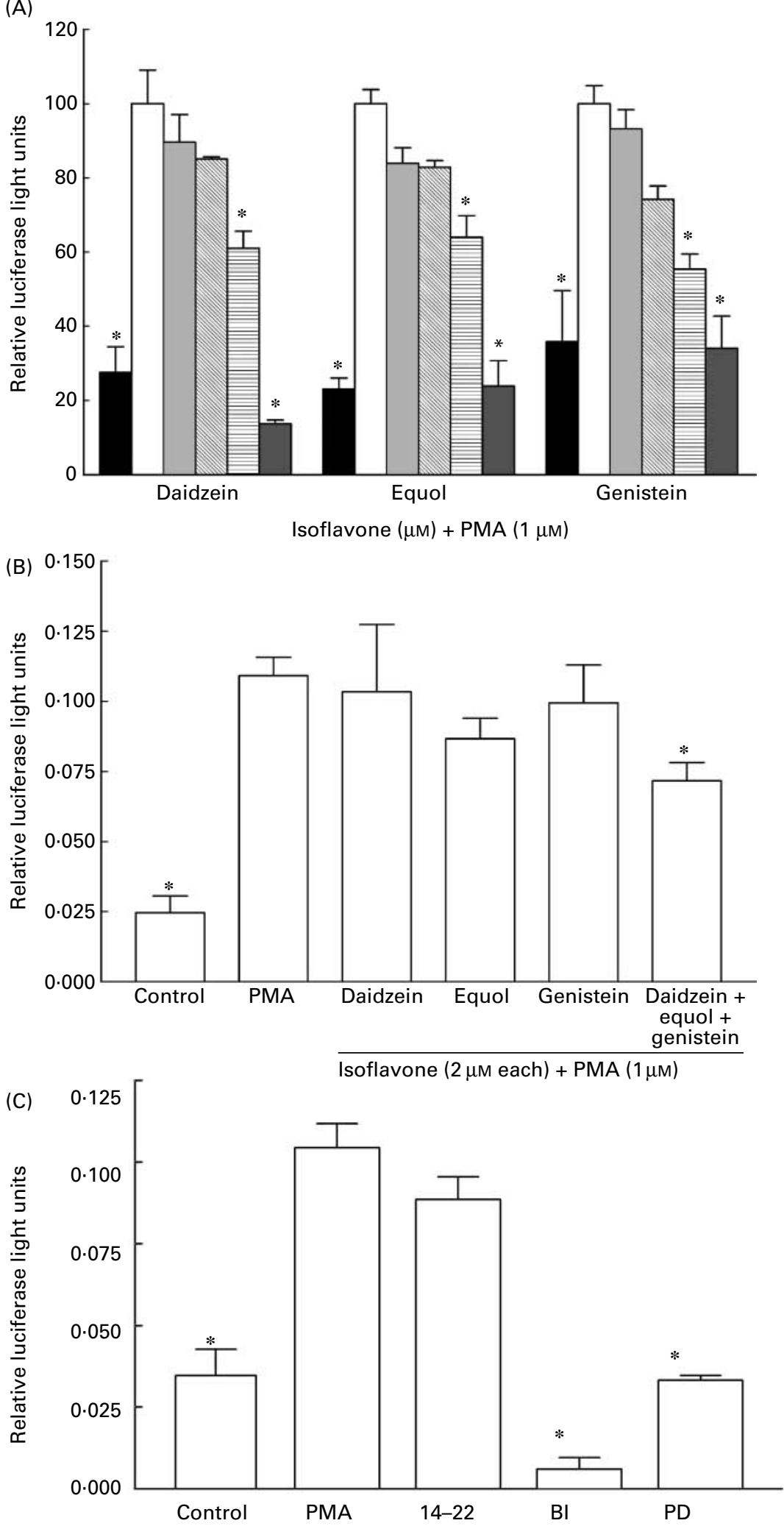

Fig. 3. Effect of soya isoflavones and protein kinase inhibitors on phorbol 12-myristate 13-acetate (PMA)-induced cyclooxygenase-2 (COX-2) promoter activities. MCF-7 cells were seeded in twenty-four-well culture plates and transfected with $h C O X-2$ reporter plasmid and Renilla luciferase control plasmid. After $6 \mathrm{~h}$ transfection, the cultures were co-treated with $1 \mu \mathrm{M}$-PMA and: (A) $0.1,1,10,100 \mu \mathrm{M}$-daidzein, equol or genistein; (B) $2 \mu \mathrm{M}$-daidzein, equol or genistein, or a combination of the isoflavones; (C) $1 \mu \mathrm{M}-14-22$ amide (14-22), $10 \mu \mathrm{g} / \mathrm{ml}$ bisindolylmaleimide I (BI) or $10 \mu \mathrm{g} / \mathrm{ml}$ PD98059 (PD). The cells were lysed and assayed for firefly and Renilla luciferase activities. The experiments were performed twice and similar results were seen. $\square \mathrm{Control} ; \square 0 \mu \mathrm{M} ; \square 0.1 \mu \mathrm{M} ; \mathbb{Q} 1 \mu \mathrm{M} ;$ 目 $10 \mu \mathrm{M} ; \square 100 \mu \mathrm{M}$. *Significant $(P<0.05)$ difference from cultures treated only with PMA. 


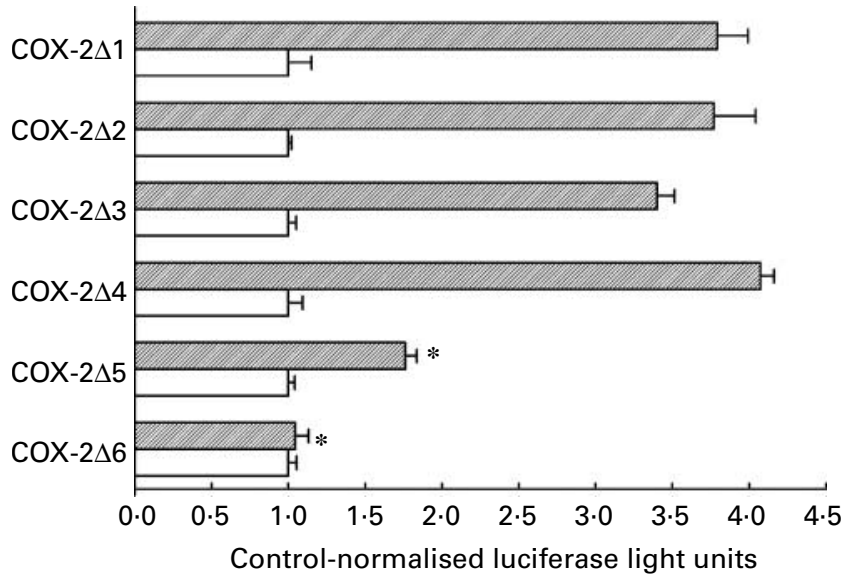

Fig. 4. Phorbol 12-myristate 13-acetate PMA-induced cyclooxygenase-2 (COX-2) promoter activity profile. MCF-7 cells were seeded in twentyfour-well culture plates and transfected with the serial truncation plasmid and Renilla luciferase plasmid. After $6 \mathrm{~h}$ transfection, the cultures were treated with or without $1 \mu \mathrm{M}$-PMA for each construct. The cells were lysed and assayed for firefly and Renilla luciferase activities. Figure 4 represents one set of two experiments performed with comparable results, and the value for each of the truncated $h C O X-2$ promoter has been normalised with its own constructed plasmid without PMA treatment. Values are means with their standard errors shown by horizontal bars, $n$ 3. $\square$ Control; $\mathbb{Q}$ PMA $1 \mu \mathrm{M}$. *Significant $(P<0.05)$ difference from the mean of COX-2 $2 \Delta 1$ among the PMA-induced cultures.

we showed that all soya isoflavones tested were able to reduce the expression of COX-2 induced by PMA, and that reduction was regulated at the transcriptional level. Equol, a metabolite of daidzein, appeared to have comparable inhibitory potency to that of its precursor isoflavone.

In a study performed on colon cells, compounds with a resorcin-type structure suppress $\beta$-galactosidase reporter transcription driven by a fragment of $h C O X-2$ promoter (Mutoh et al. 2000). Genistein has been demonstrated to inhibit the promoter in these colon cells. The same phytochemical has not, however, been shown to inhibit COX-2 expression in human peripheral leucocytes stimulated with lipopolysaccharide and interferon- $\gamma$ (Richard et al. 2005). Differences in cell type and stimulus may account for the negative result. In the present study, all soya isoflavones inhibited promoter activity in MCF-7 cells. Daidzein and equol also have the resorcin type of structure, as does genistein. The mechanism of COX-2 expression inhibition in breast cells may be comparable to that in colon cells.

The $h C O X-2$ gene has many putative transcriptional regulatory elements other than AP-1, for example AP-2, nuclear factor of activated $\mathrm{T}$ cells, nuclear factor for interleukin 6 , nuclear factor $\mathrm{\kappa B}$ and specificity protein-1, in its promoter region (Kosaka et al. 1994). The functionality of these response elements is dependent on the specific stimuli and cell type. In the present study, the serial truncation promoter assay indicated that the binding activity of AP-1/CREB and unidentified elements within the sequence $(-578 /-70)$ was activated by PMA. The activity of AP-1/CREB was suppressed by soya isoflavones. The suppression by soya isoflavones of PMA-induced COX$2 \Delta 1$ activity was about $40 \%$, whereas that of PMA-induced COX-2 $\Delta 5$ activity was about $50 \%$. Despite the fact that PMA induced other elements in the $-578 /-70$ region of $h C O X-2$, the effect of the isoflavones on AP-1/CREB appeared to be fully responsible for the suppression.

In the present study, the inhibitory effect of soya isoflavones on COX-2 expression through the inhibition of AP-1/CREB was also demonstrated. Inhibitors of PKC, PKA and MAPK were employed to establish a possible signalling pathway involved. Although the PKC and MAPK inhibitors could inhibit COX-2 $\Delta 1$ promoter activity, reporter assay results from the truncated promoter with and without the AP-1/CREB sequence indicated that the actions of the inhibitors were drastically different. Bisindolylmaleimide I increased, whereas PD98059 decreased, the luciferase activity generated from AP-1/CREB-containing reporter plasmid. It appeared that the pattern of $h C O X-2$ promoter suppression by soya isoflavones was consistent with that of the MAPK inhibitor PD98059. The idea that soya isoflavones suppress COX-2 expression via a modulation of the MAPK pathway warrants further investigation. Tamoxifen can activate AP-1, which may lead to tamoxifen resistance in breast cancer cells (Altundag et al. 2004). The suppression of AP-1/CREB by soya isoflavones in this study provides the basis for studying these phytocompounds as complementary supplements in tamoxifen therapy.

Previous studies have shown that dietary phytochemicals may inhibit PMA-induced COX-2 expression in human mammary and gastrointestinal epithelial cells, and differential effects in terms of AP-1 binding to its promoter have been reported. Curcumin suppresses COX-2 expression in gastrointestinal cells via an AP-1-dependent mechanism (Zhang et al. 1999). In mammary cells, resveratrol (Subbaramaiah et al. 1998) and retinoic acid (Subbaramaiah et al. 2002a) inhibit expression through AP-1 binding, whereas catechin curbs expression in an AP-1independent mechanism (Kundu et al. 2003). In addition, resveratrol inhibits PKC $\alpha$ - and ERK-1-induced $h C O X-2$ promoter activities (Subbaramaiah et al. 1998). The magnitude of inhibition seen in the present investigation was comparable to that of resveratrol in the breast 184B5/HER cell line. In addition, the signalling pathway mediated by ERK-1, not PKC, was consistent with the suppression pattern of soya isoflavones on $h C O X-2$ promoter activity.

The dietary relevance of various genistein dosages in man has been reasonably established over many years of research. The major soya isoflavone metabolite in women is the glucuronide form, and the aglycone genistein constitutes only about one quarter of the total genistein present in the plasma (Zhang et al. 2003). In a high soya-consuming country such as Japan, the average plasma concentration of total genistein is about $0.5 \mu \mathrm{mol} / 1$ in women (Morton et al. 2002). Supplementation may give rise to plasma levels of about $1 \mu \mathrm{mol}$ aglycone genistein/l (Izumi et al. 2000). However, the additive effect of various soyabean phytochemicals has largely been overlooked. Some additive effect of isoflavones was illustrated in the present COX-2 promoter study. This collective force may be sufficient to initiate some physiological changes compared with those observed at high genistein concentrations.

In conclusion, we demonstrated that soya isoflavones down regulated COX-2 expression induced by PMA; the major mechanism behind this could be the counteracting of AP-1/CREB activity. The findings might have important implications in the chemopreventive application of soya isoflavones. 

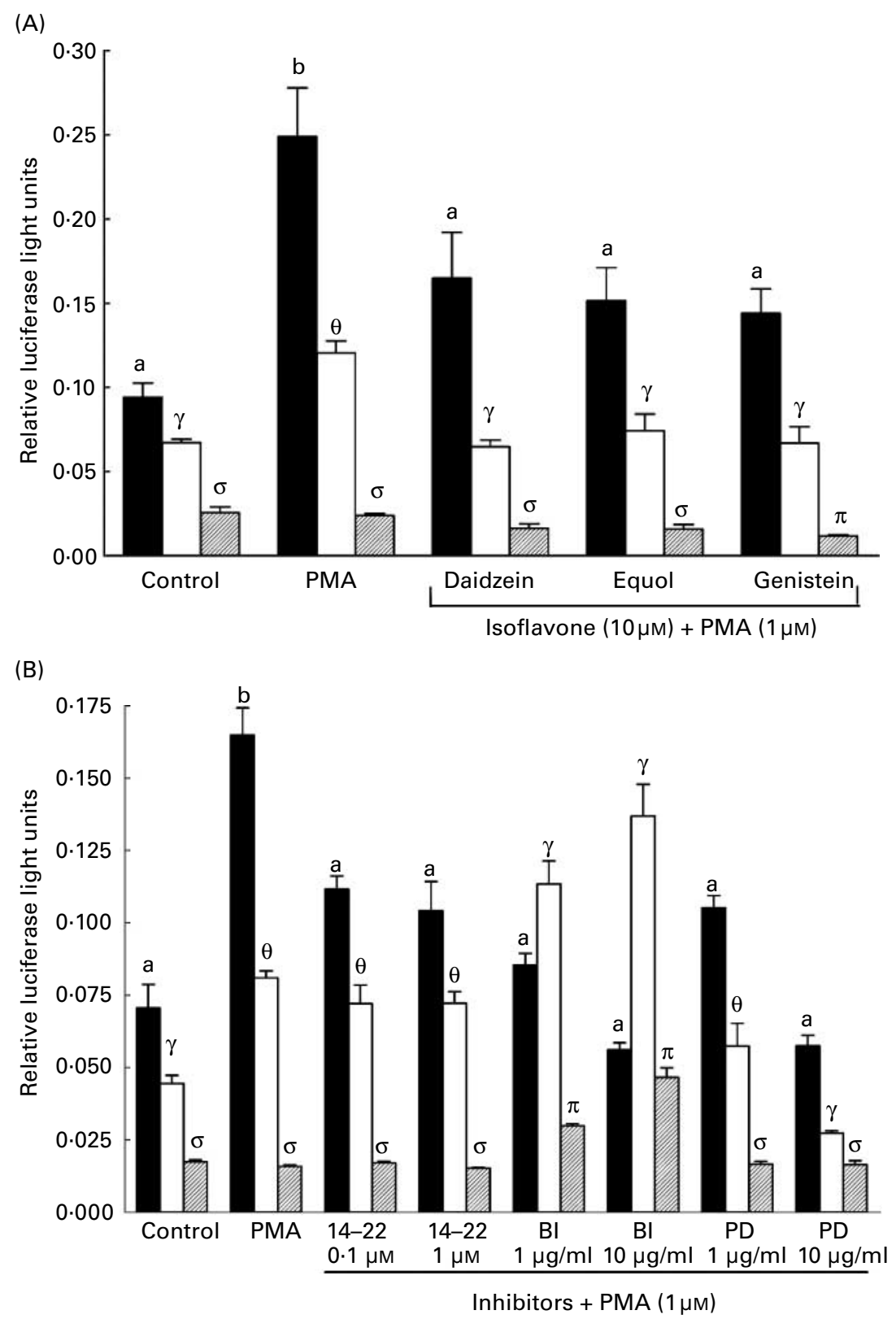

Fig. 5. Effect of soya isoflavones and protein kinase inhibitors on phorbol 12-myristate 13-acetate (PMA)-induced cyclooxygenase-2 (COX-2) COX-2 $\Delta 5$ and $\Delta 6$ activities. MCF-7 cells were seeded in twenty-four-well culture plates and transfected with the truncated $h C O X-2$ reporter plasmid and Renilla luciferase plasmid. After $6 \mathrm{~h}$ transfection, the cultures were co-treated with $1 \mu \mathrm{M}$-PMA and $10 \mu \mathrm{M}$-soya isoflavone $(\mathrm{A})$ or protein kinase inhibitors (B). The cells were lysed and assayed

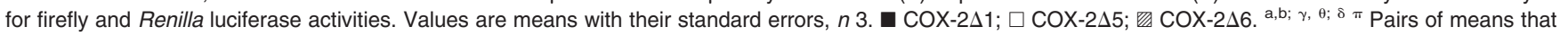
are significantly $(P<0.05)$ different.

\section{Acknowledgements}

This study was supported by the Chinese University of Hong Kong Direct Grant for Research code no. 2041112. The authors would like to thank Dr Howard Glauert of the University of Kentucky, USA, for critical review of this manuscript. Some of the data were presented at the American Association for Cancer Research annual meeting, Orlando, FL, USA in 2004.

\section{References}

Allred CD, Allred KF, Ju YH, Clausen LM, Doerge DR, Schantz SL, Korol DL, Wallig MA \& Helferich WG (2004) Dietary genistein results in larger MNU-induced, estrogen-dependent mammary tumours following ovariectomy of Sprague-Dawley rats. Carcinogenesis 25, 211-218.

Altundag K, Altunday O, Gunduz M \& Arun B (2004) Possible interaction between activator protein-1 and proto-oncogene B-cell lymphoma gene 6 in breast cancer patients resistant to tamoxifen. Med Hypotheses 63, 823-826.

Arun B, Zhang H, Mirza NQ, Hortobogyi GN, Hung MC \& Meric F (2001) Growth inhibition of breast cancer cells by celecoxib. Breast Cancer Res Treat 69, 234 (abstract).

Dong Z, Birrer MJ, Watts RG, Matrisian LM \& Colburn NH (1994) Blocking of tumour promoter-induced AP-1 activity inhibits induced transformation in JB6 mouse epidermal cells. Proc Natl Acad Sci USA 91, 609-613. 
Greenwald P (2004) Clinical trials in cancer prevention: current results and perspectives for the future. $J$ Nutr 134, 3507S-3512S.

Gupta RA \& DuBois RN (2001) Colorectal cancer prevention and treatment by inhibition of cyclooxygenase-2. Nat Rev Cancer 1, 11-21.

Harris RE, Alshafie GA, Abou-Issa H \& Seibert K (2000) Chemoprevention of breast cancer in rats by celecoxib, a cyclooxygenase 2 inhibitor. Cancer Res 60, 2101-2103.

Howe LR, Subbaramaiah K, Brown AMC \& Dannenberg AJ (2001) Cyclooxygenase-2: A target for the prevention and treatment of breast cancer. Endocr Relat Cancer 8, 97-114.

Howe LR, Subbaramaiah K, Patel J, et al. (2002) Celecoxib, a selective cyclooxygenase-2 inhibitor, protects against human epidermal growth factor receptor 2 (HER-2)/neu-induced breast cancer. Cancer Res 62, 5405-5407.

Izumi T, Piskula MK, Osawa $\mathrm{S}$, Obata $\mathrm{A}$, Tobe $\mathrm{K}$, Saito $\mathrm{M}$, Kataoka S, Kubota Y \& Kikuchi M (2000) Soy isoflavone aglycones are absorbed faster and in higher amounts than their glucosides in humans. J Nutr 130, 1695-1699.

Kosaka T, Miyata A, Ihara H, Hara S, Sugimoto T, Takeda O, Takahashi E \& Tanabe T (1994) Characterization of the human gene (PTGS2) encoding prostaglandin-endoperoxide synthase 2. Eur J Biochem 221, 889-897.

Kundu JK, Na H-K, Chun K-S, Kim Y-K, Lee SJ, Lee SS, Lee O-S, Sim Y-C \& Surh Y-J (2003) Inhibition of phorbol ester-induced COX-2 expression by epigallocatechin gallate in mouse skin and cultured human mammary epithelial cells. $J$ Nutr 133, 3805S-3810S

Leung LK \& Wang TT (2000) Bcl-2 is not reduced in the death of MCF7 cells at low genistein concentration. J Nutr 130, 2922-2926.

Livak KJ \& Schmittgen TD (2001) Analysis of relative gene expression data using real-time quantitative PCR and the 2(-Delta Delta C(T)) Method. Methods 25, 402-408.

Miller C, Zhang M, He Y, Zhao J, Pelletier J-P, Martel-Pelletier J \& Di Battista JA (1998) Transcriptional induction of cyclooxygenase2 gene by okadaic acid inhibition of phosphatase activity in human chondrocytes: co-stimulation of AP-1 and CRE nuclear binding proteins. J Cell Biochem 69, 392-413.

Morton MS, Arisaka O, Miyake N, Morgan LD \& Evans BA (2002) Phytoestrogen concentrations in serum from Japanese men and women over forty years of age. J Nutr 132, 3168-3171.

Murata M, Midorikawa K, Koh M, Umezawa K \& Kawanishi S (2004) Genistein and daidzein induce cell proliferation and their metabolites cause oxidative DNA damage in relation to isoflavone-induced cancer of estrogen-sensitive organs. Biochemistry $\mathbf{4 3}, 2569-2577$.

Mutoh M, Takahashi M, Fukuda K, Matsushima-Hibiya Y, Mutoh H, Sugimura T \& Wakabayshi K (2000) Carcinogenesis 21, 959-963.

Nakatsugi S, Hhta T, Kawamori T, Mutoh M, Tanigawa T, Watanabe K, Sugie S, Sugimura T \& Wakabayahi K (2000) Chemoprevention by nimesulide, a selective cyclooxygenase-2 inhibitor, of 2-amino-1-methyl-6-phenylimidazol [4,5-b]pyridine (PhIP)induced mammary gland carcinogenesis in rats. Japan $J$ Cancer Res 91, 886-892.

Po LS, Wang TT, Chen ZY \& Leung LK (2002) Genistein-induced apoptosis in MCF-7 cells involves changes in Bak and Bcl-x without evidence of anti-oestrogenic effects. $B r J$ Nutr 88, 463-469.

Prosperi JR, Mallery SR, Kigerl KA, Erfurt AA \& Robertson FM (2004) Invasive and angiogenic phenotype of MCF-7 human breast tumour cells expressing human cyclooxygenase-2. Prostaglandins Other Lipid Mediat 73, 249-264.

Richard N, Porath D, Radspieler A \& Schwager J (2005) Effects of resveratrol, piceatannol, tri-acetoxystilbene, and genistein on the inflammatory response of human peripheral blood leukocytes. Mol Nutr Food Res 49, 431-442.

Simstein R, Burow M, Parker A, Weldon C \& Beckman B (2003) Apoptosis, chemoresistance, and breast cancer: insights from the MCF-7 cell model system. Exp Biol Med (Maywood) 228, 995-1003.

Singh B \& Lucci A (2002) Role of cyclooxygenase-2 in breast cancer. J Surg Res 108, 173-179.

Soslow R, Dannenberg A, Rush D, Woerner BM, Khan KN, Masferrer J \& Koki A (2000) COX-2 is expressed in human pulmonary, colonic, and mammary tumours. Cancer 89, 2637-2645.

Subbaramaiah K, Chung WJ, Michaluart P, Telang N, Tanabe T, Inoue H, Jang M, Pezzuto JM \& Dannenberg AJ (1998) Resveratrol inhibits cyclooxygenase-2 transcription and activity in phorbol ester-treated human mammary epithelial cells. J Biol Chem 273, 21875-21882.

Subbaramaiah K, Cole PA \& Dannenberg AJ (2002a) Retinoids and carnosol suppress cyclooxygenase-2 transcription by CREB-binding protein/p300-dependent and independent mechanisms. Cancer Res 62, 2522-2530.

Subbaramaiah K, Norton L, Gerald W \& Dannenberg AJ (2002b) Cyclooxygenase-2 is overexpressed in HER-2/neu-positive breast cancer - evidence for involvement of AP-1 and PEA3. J Biol Chem 277, 18649-18657.

Sun Y, Wenger L, Brinckerhoff CE, Misra RR \& Cheung HS (2002) Basic calcium phosphate crystals induce matrix metalloproteinase1 through the Ras/mitogen-activated protein kinase/c-fos/AP-1/ metalloproteinase 1 pathway. J Biol Chem 277, 1544-1552.

Takahashi Y, Kawahara F, Noguchi M, Miwa K, Sato H, Seiki M, Inoue H, Tanabe T \& Yoshimoto T (1999) Activation of matrix metalloproteinase-2 in human breast cancer cells over-expressing cyclooxygenase-1 or -2. FEBS Letts 460, 145-148.

Trifan OC \& Hla T (2003) Cyclooxygenase-2 modulates cellular growth and promotes tumorigenesis. J Cell Mol Med 7, 207-222.

Upadhyaya P \& El Bayoumy K (1998) Effect of dietary soy protein isolate, genistein, and 1,4-phenylenebis(methylene)selenocyanate on DNA binding of 7,12-dimethyl-benz[a]anthracene in mammary glands of CD rats. Oncol Rep 5, 1541-1545.

Zhang F, Altorki NK, Mestre JR, Subbaramaiah K \& Dannenberg AJ (1999) Curcumin inhibits cyclooxygenase-2 transcription in bile acid- and phorbol ester-treated human gastrointestinal epithelial cells. Carcinogenesis 20, 445-451.

Zhang Y, Hendrich S \& Murphy PA (2003) Glucuronides are the main isoflavone metabolites in women. J Nutr 133, 399-404.

Ziegler RG, Hoover RN, Pike MC, Hidesheim A, Nomura AM, West DW, Wu-Williams AAH, Kolonel LN, Horn-Ross PL \& Rosenthal JF (1993) Migration patterns and breast cancer risk in Asian-American women. J Natl Cancer Inst 85, 1819-1827. 